\title{
Co-operative inhibitory effects of hydrogen peroxide and iodine against bacterial and yeast species
}

\author{
Elena I Zubko and Mikhajlo K Zubko*
}

\begin{abstract}
Background: Hydrogen peroxide and iodine are powerful antimicrobials widely used as antiseptics and disinfectants. Their antimicrobial properties are known to be enhanced by combining them with other compounds. We studied co-operative inhibitory activities (synergism, additive effects and modes of growth inhibition) of hydrogen peroxide and iodine used concurrently against 3 bacterial and 16 yeast species.

Results: Synergistic or additive inhibitory effects were shown for hydrogen peroxide and iodine mixtures against all 19 species used in the study. Both biocides were mostly cidal individually and in mixtures against Pseudomonas aeruginosa and Staphylococcus aureus. Both compounds manifested static inhibitory effects individually, but their mixtures were synergistically cidal for Saccharomyces cerevisiae and Escherihia coli. Cells of S. cerevisiae treated with hydrogen peroxide and iodine-hydrogen peroxide mixture produced increased numbers of respiratory deficient mutants indicating genotoxic effects.

Conclusion: lodine and hydrogen peroxide used concurrently interact synergistically or additively against a range of prokaryotic and eukaryotic microorganisms. The study provides an insight as to how these traditional antimicrobials could be used more effectively for disinfection and antisepsis. In addition, a simple approach is proposed for scoring genotoxicity of different biocides by using the budding yeast system.
\end{abstract}

Keywords: Antimicrobials, Synergism, lodine, Hydrogen peroxide, Escherichia, Pseudomonas, Staphylococcus, Saccharomyces, Candida, Genotoxicity

\section{Background}

Antimicrobials are extensively utilized for infection and microbial control in health care, industry and the environment [1]. They are also used for medical treatments [2]. Combining antimicrobials could enhance their activities (via additive effects or synergism) and could help to overcome acquired microbial resistance to single chemicals [1].

Iodine $\left(\mathrm{I}_{2}\right)$ and hydrogen peroxide $\left(\mathrm{H}_{2} \mathrm{O}_{2}\right)$ are oxidizing agents with a long history of usage as antimicrobials [1-6]. Iodine is a halogen releasing agent manifesting rapid bactericidal, fungicidal, virucidal and sporicidal effects caused by inhibiting DNA synthesis and attacking amino acids, nucleotides and fatty acids [1,7]. It is often

\footnotetext{
* Correspondence: m.zubko@mmu.ac.uk

School of Healthcare Science, Manchester Metropolitan University, John Dalton Building, Chester St, Manchester M1 5GD, UK
}

used in complexes (iodophores) with solubilising agents $[1,7]$. Hydrogen peroxide is a peroxygen used for efficient control of various bacteria (especially Grampositive), their spores, yeasts and viruses - due to the formation of free $\mathrm{OH}$-radicals breaking DNA and oxidizing thiol-groups of proteins and lipids [1]. Both compounds are common antiseptics and disinfectants in topical skin therapy $[4,8]$, wound healing $[2,7,9-11]$, preparation of preoperative sites [12], control of gingival plaques [13], treating biofilms [14] and Fournier's gangrene [15], disinfection of catheters [16] and other surfaces [17], industrial treatments of fish eggs $[18,19]$, reducing bacterial pathogens on fruits [20], purification of water systems [21] and many other processes.

Some problems associated with side effects and acquired microbial resistance to single antimicrobials could be minimised by using them at lower concentrations in combination. Prerequisites for decreasing 
concentrations of biocides should be their synergistic or additive effects in mixtures. Increased antimicrobial activities of hydrogen peroxide were shown in combinations with other compounds including hypothiocyanite [22], sodium bicarbonate [23], rifampicin [24], neucoproine [25], chlorhexidine [26], different organic acids $[20,27]$ as well as with UV-irradiation [28]. Synergies were reported also for iodine combined with an essential oil [29], hyaluronan [10], chlorhexidine gluconate [30], polyacrylonitrile [31].

A few sporadic studies on combining iodine and hydrogen peroxide have been reported [32-34], but the nature of interactions between these compounds and the potential use of this combination against various microorganisms were not studied. In this study, we compared inhibitory effects and modes of action of iodine and hydrogen peroxide used separately and in mixtures against 3 bacterial and 16 yeast species.

\section{Results and discussion}

Enhanced growth inhibition of 16 yeast species exposed to hydrogen peroxide and iodine concurrently

In preliminary experiments, $2 \mathrm{mM}$ iodine or $6 \mathrm{mM}$ hydrogen peroxide (in solid YEPD medium) completely inhibited the growth of all tested S. cerevisiae haploid strains (data not shown). In spot tests carried out for 16 different yeast species (Figure 1; Additional file 1: Table S1) on solid YEPD medium containing $1 \mathrm{mM}$ iodine and $1.5 \mathrm{mM}$ hydrogen peroxide, haploid strains DLY 640 and DLY 641 ( $S$. cerevisiae) were the most sensitive to iodine; strains Turbo, ade-1 (S. cerevisiae), GDH 2346, NCPF

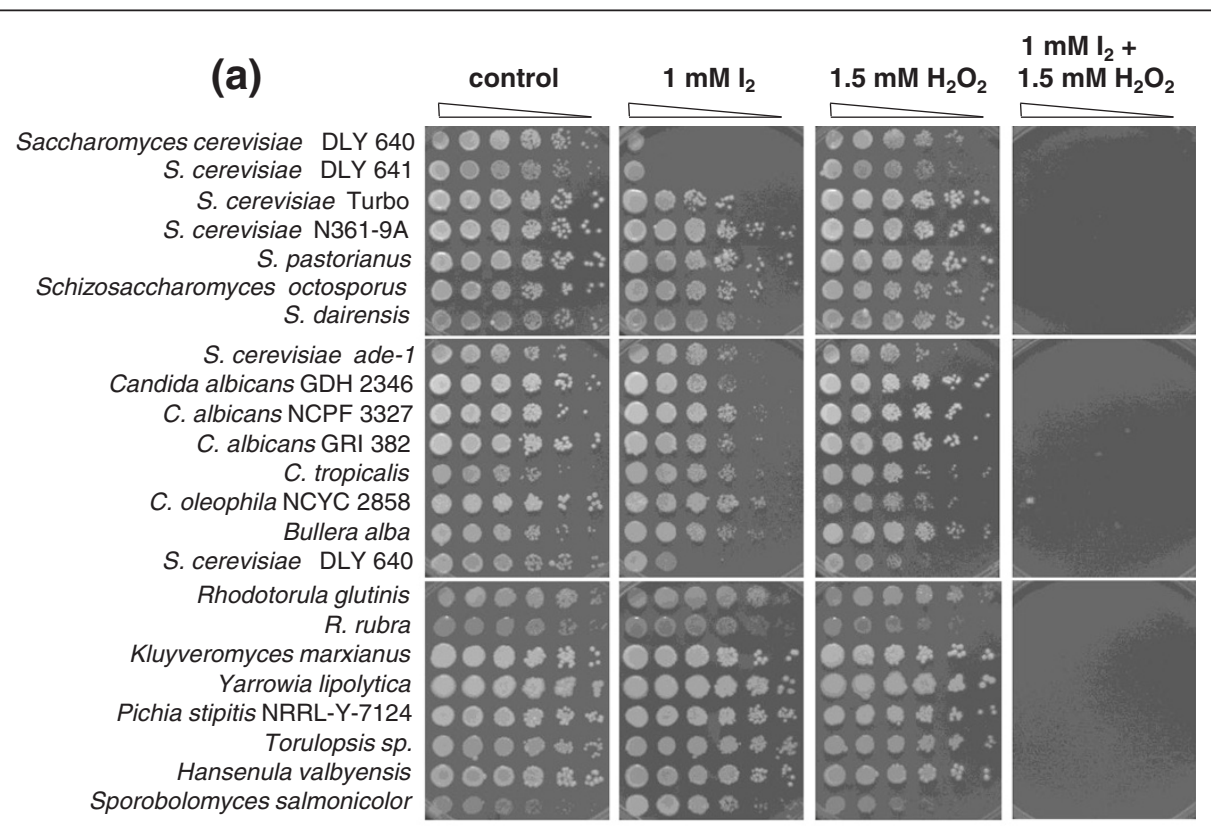

(b)

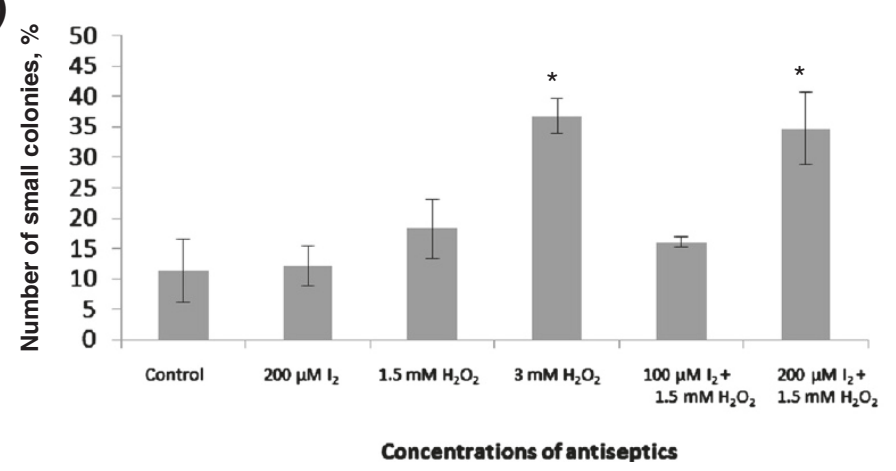

Figure 1 Co-operative effects of hydrogen peroxide and iodine on yeast species. (a) The enhancement in the inhibition of yeast growth by hydrogen peroxide and iodine used in the mixture. Six serial dilutions of each culture were plated in each horizontal row, with most concentrated suspensions on the left. (b) Enhanced incidence of small colonies in yeast cells treated with hydrogen peroxide and with the mixture iodine-hydrogen peroxide. Stars indicate significantly different values $(P<0.05)$. 
3327, GRI 382 (C. albicans), species C. tropicalis and Bullera alba were slightly inhibited by this biocide; the remainder of the strains were not affected by iodine (Figure 1a). None of the strains was inhibited by $1.5 \mathrm{mM}$ hydrogen peroxide. The mixture of both biocides completely inhibited the growth of all species.

These data show that all yeast species manifested cessation of their growth in the response to concurrent applications of iodine and hydrogen peroxide at concentrations allowing growth when the antiseptics were used separately. Therefore, it is very likely that this cooperative inhibitory capacity of the iodine-hydrogen peroxide mixture could be extended to many others, if not all, yeast species. Depending on the extent of microbial growth inhibition by any two combined substances, the interactions between them could be described as synergistic or additive $[1,35]$. To potentially extrapolate our results on prokaryotes, we investigated in more details the nature of inhibitory effects of iodine and hydrogen peroxide used separately and concurrently against three bacterial species, alongside with a budding yeast strain.

\section{Separate antimicrobial effects of hydrogen peroxide and iodine}

We tested antimicrobial effects of hydrogen peroxide and iodine against budding yeast (S. cerevisiae) and three bacterial species (Escherichia coli, Pseudomonas aeruginosa and Staphylococcus aureus) grown in liquid culture.

MIC values of each compound varied for different species (Additional file 2: Table S2). S. cerevisiae and S. aureus were more sensitive to iodine than E. coli and P. aeruginosa. No visible growth of $S$. cerevisiae was detectable at $300 \mu \mathrm{M} \mathrm{I}_{2} .400 \mu \mathrm{M}$ was a critical iodine concentration for $S$. aureus. The growth inhibition of $E$. coli and $P$. aeruginosa was observed only at $600 \mu \mathrm{M} \mathrm{I}_{2}$.

S. aureus showed the highest sensitivity to $\mathrm{H}_{2} \mathrm{O}_{2}$. As no visible growth was detected at $200 \mu \mathrm{M} \mathrm{H}_{2} \mathrm{O}_{2}$, this concentration was taken as MIC. MIC of $\mathrm{H}_{2} \mathrm{O}_{2}$ for $E$. coli was $800 \mu \mathrm{M}$, for $S$. cerevisiae and $P$. aeruginosa it was $4 \mathrm{mM}$, which is 20 times higher than for $S$. aureus (Table S2).

In conclusion, various microorganisms manifested different sensitivities to iodine and hydrogen peroxide.

\section{Combined inhibitory effects of hydrogen peroxide and iodine}

In mixtures of hydrogen peroxide and iodine, inhibitory concentrations were lower than for the individual compounds in liquid cultures of all tested species (Table 1). Criteria for synergism or additive effects are based on calculations of FIC and FICs values. FIC of a compound is the ratio of MIC value for this compound in the mixture to MIC value for this compound alone. The lower the FIC value is, the more effective inhibitory effect takes place in a mixture. The sum of FIC values (FICs = $\mathrm{FIC}_{\mathrm{a}}+\mathrm{FIC}_{\mathrm{b}}$ ) determines interpreting the mode of inhibitory interactions between individual compounds $(a$ and $b$ ) in a mixture $[26,36]$. For $E$. coli, at different combinations of hydrogen peroxide-iodine concentrations FICs indexes were in range $0.58-0.79$ (less than 1 ) that could be interpreted as a strong additive interaction or a weak synergism [26,37]. Similar results were obtained for $P$. aeruginosa with FICs values between 0.58 and 0.75 . For $S$. cerevisiae and $S$. aureus the effect of the interaction was additive, with FICs indexes around 1. Taking the definition of synergism at FICs values less than 0.5 $[27,38]$ we could interpret our results as additive inhibitory effects.

\section{Recovery of inhibited cells}

To test modes of inhibition (cell death or growth arrest) caused by hydrogen peroxide and iodine, cells inhibited by treatments were washed twice, spread on plates without antimicrobials, and incubated under conditions permissive for growth. Different species manifested diverse abilities to recover the growth after inhibition by individual and mixed compounds.

Cells of $P$. aeruginosa treated with the individual compounds at MICs $(600 \mu \mathrm{M}$ for iodine and $4 \mathrm{mM}$ for hydrogen peroxide) did not recover (Additional file 3: Figure S1). No recovery of $P$. aeruginosa was also found after combined treatments, even at concentrations lower than MIC values for each compound. For example, the mixture $\left(200 \mu \mathrm{M} \mathrm{I}_{2}+1.5 \mathrm{mM} \mathrm{H}_{2} \mathrm{O}_{2}\right)$, where concentration of iodine was 3 times lower and concentration of $\mathrm{H}_{2} \mathrm{O}_{2}$ was 2.7 times lower than for individual MICs, killed cells of $P$. aeruginosa irreversibly.

There were no viable cells after treatment of $S$. aureus with $400 \mu \mathrm{M}$ iodine (MIC), but substantial amounts of cells were viable after treatment with $250 \mu \mathrm{M}$ hydrogen peroxide (MIC for $\mathrm{H}_{2} \mathrm{O}_{2}$ is $200 \mu \mathrm{M}$ ). Small amounts of CFU were found in 2 out of 3 tested combinations of both antimicrobials, $\left(250 \mu \mathrm{M} \mathrm{I}_{2}+75 \mu \mathrm{M} \mathrm{H}_{2} \mathrm{O}_{2}\right)$ and $\left(100 \mu \mathrm{M} \mathrm{I}_{2}+150 \mu \mathrm{M} \mathrm{H}_{2} \mathrm{O}_{2}\right)$, with 33 colonies and 32 colonies respectively (both from undiluted cultures). No colonies appeared from the mixture $\left(300 \mu \mathrm{M} \mathrm{I}_{2}+\right.$ $150 \mu \mathrm{M} \mathrm{H}_{2} \mathrm{O}_{2}$ ). We concluded that for $\mathrm{S}$. aureus iodine is more cidal than hydrogen peroxide (Additional file 3: Figure S2).

The above data suggest that cells of $P$. aeruginosa and $S$. aureus were killed more effectively by iodine and hydrogen peroxide used in mixtures rather than individually, and that inhibitory effects were achieved at lower concentrations of the antiseptics due to synergism.

Cells of S. cerevisiae treated either with iodine or hydrogen peroxide recovered after applications of these compounds at all tested concentrations. No recovery was observed after combined treatments at 
Table 1 Growth responses of S. cerevisiae, E. coli, S. aureus and $P$. aeruginosa to $I_{2}$ and $\mathrm{H}_{2} \mathrm{O}_{2}$ combined at various concentrations in liquid growth media

\begin{tabular}{|c|c|c|c|c|c|c|c|}
\hline \multicolumn{8}{|c|}{ S. cerevisiae } \\
\hline $\mathrm{I}_{2} \mathrm{VH}_{2} \mathrm{O}_{2}^{*}$ & $0 \mu \mathrm{M}$ & $1 \mathrm{mM}$ & $1.5 \mathrm{mM}$ & $2 \mathrm{mM}$ & $2.5 \mathrm{mM}$ & $3 \mathrm{mM}$ & $4 \mathrm{mM}$ \\
\hline $0 \mu \mathrm{M}$ & +++ & +++ & +++ & +++ & +++ & +++ & - \\
\hline $20 \mu \mathrm{M}$ & +++ & +++ & +++ & +++ & +++ & +++ & \\
\hline $25 \mu \mathrm{M}$ & +++ & +++ & +++ & +++ & +++ & ++ & \\
\hline $50 \mu \mathrm{M}$ & +++ & +++ & +++ & +++ & +++ & + & \\
\hline $75 \mu \mathrm{M}$ & +++ & +++ & +++ & +++ & +++ & $-{ }^{1}$ & \\
\hline $100 \mu \mathrm{M}$ & +++ & +++ & +++ & +++ & -0.95 & - & \\
\hline $150 \mu \mathrm{M}$ & +++ & +++ & +++ & +++ & - & - & \\
\hline $200 \mu \mathrm{M}$ & +++ & +++ & ++ & -1.16 & - & - & \\
\hline $250 \mu \mathrm{M}$ & +++ & +++ & ++ & -1.33 & - & - & \\
\hline $300 \mu \mathrm{M}$ & - & - & - & - & - & - & \\
\hline \multicolumn{8}{|l|}{ E. coli } \\
\hline $\mathrm{I}_{2} \backslash \mathrm{H}_{2} \mathrm{O}_{2}$ & $0 \mu \mathrm{M}$ & $100 \mu \mathrm{M}$ & $200 \mu \mathrm{M}$ & $400 \mu \mathrm{M}$ & $600 \mu \mathrm{M}$ & $800 \mu \mathrm{M}$ & $1 \mathrm{mM}$ \\
\hline $0 \mu \mathrm{M}$ & +++ & +++ & +++ & +++ & +++ & - & \\
\hline $50 \mu \mathrm{M}$ & +++ & +++ & +++ & $-^{0.58}$ & - & - & \\
\hline $100 \mu \mathrm{M}$ & +++ & +++ & +++ & - & - & - & \\
\hline $200 \mu \mathrm{M}$ & +++ & +++ & ++ & - & - & - & \\
\hline $300 \mu \mathrm{M}$ & +++ & +++ & -0.75 & - & - & - & \\
\hline $400 \mu \mathrm{M}$ & +++ & -0.79 & - & - & - & - & \\
\hline $500 \mu \mathrm{M}$ & - & - & - & - & - & - & \\
\hline
\end{tabular}

S. aureus

\begin{tabular}{llllllr}
\hline $\mathrm{I}_{2} \backslash \mathrm{H}_{2} \mathrm{O}_{2}$ & $0 \mu \mathrm{M}$ & $75 \mu \mathrm{M}$ & $100 \mu \mathrm{M}$ & $150 \mu \mathrm{M}$ & $200 \mu \mathrm{M}$ & $300 \mu \mathrm{M}$ \\
$0 \mu \mathrm{M}$ & +++ & +++ & +++ & +++ & - & - \\
$100 \mu \mathrm{M}$ & +++ & +++ & ++ & ++ & - & - \\
$150 \mu \mathrm{M}$ & +++ & ++ & ++ & - & - & - \\
$200 \mu \mathrm{M}$ & +++ & ++ & -1 & - & - & - \\
$250 \mu \mathrm{M}$ & +++ & $-{ }^{1}$ & - & - & - & - \\
$300 \mu \mathrm{M}$ & +++ & - & - & - & - \\
$400 \mu \mathrm{M}$ & - & - & - & - & -
\end{tabular}

P. aeruginosa

\begin{tabular}{|c|c|c|c|c|c|c|c|}
\hline $\mathrm{I}_{2} \backslash \mathrm{H}_{2} \mathrm{O}_{2}$ & $0 \mathrm{mM}$ & $1 \mathrm{mM}$ & $1.5 \mathrm{mM}$ & $2 \mathrm{mM}$ & $2.5 \mathrm{mM}$ & $3 \mathrm{mM}$ & $4 \mathrm{mM}$ \\
\hline $0 \mu \mathrm{M}$ & +++ & +++ & +++ & +++ & +++ & + & - \\
\hline $25 \mu \mathrm{M}$ & +++ & +++ & +++ & + & $-^{0.66}$ & - & - \\
\hline $50 \mu \mathrm{M}$ & +++ & +++ & +++ & -0.58 & - & - & - \\
\hline $100 \mu \mathrm{M}$ & +++ & +++ & + & - & - & - & - \\
\hline $200 \mu \mathrm{M}$ & +++ & +++ & $-^{0.71}$ & - & - & - & - \\
\hline $250 \mu \mathrm{M}$ & +++ & ++ & - & - & - & - & - \\
\hline $300 \mu \mathrm{M}$ & +++ & $-^{0.75}$ & - & - & - & - & - \\
\hline $600 \mu \mathrm{M}$ & - & - & - & - & - & - & - \\
\hline
\end{tabular}

*Concentrations for $\mathrm{H}_{2} \mathrm{O}_{2}$ are shown in horizontal rows; concentrations for $\mathrm{I}_{2}$ are shown in vertical rows. The absence of growth is indicated by the sign "-". FICs index values are shown as numbers near correspondent "-" sign. Signs " +++ ", " ++ " and " + " indicate different degrees of growth. The results were recorded after 2 days of cultivation at $30^{\circ} \mathrm{C}$ (for S. cerevisiae), or after $1-2$ days of cultivation at $37^{\circ} \mathrm{C}$ (for E. coli, S. aureus and P. aeruginosa). 
lower concentrations (Additional file 3: Figure S3). Similarly, no recoveries of cell divisions were observed after combined treatments of E. coli with two antiseptics (cidal effects), while recoveries took place after individual treatments with either iodine or hydrogen peroxide (Additional file 3: Figure S4). These data indicate that at least some proportions of treated cells of $S$. cerevisiae and E. coli were not able to divide due to static effects. The combined treatments of these species resulted in complete loss of their viabilities, implying that synergism led to cidal action.

Cidal effects are more advantageous than static ones, in terms of effectiveness. Therefore, combined treatments with iodine-hydrogen peroxide could be more effective approach in many aspects of disinfection and topical treatments associated with these antiseptics. Particular advantages of the combined treatments could be related to reduced concentrations of the antimicrobials that could be important for reducing their side effects $[39,40]$. Another advantage would be prevention of microbial resistance that could be acquired to single biocides [41,42].

Our experiments were carried out in vitro on pure cultures of microorganisms. Application of the co-operative inhibitory effects to in vivo clinical conditions including potentially mixed infections and biological substrates will require additional trials. However, a recent clinical study demonstrated effective reductions of post-operational infections by using combined treatments with PVP-iodine and hydrogen peroxide after spine surgeries [33].

\section{lodine enhances incidence of respiration deficiencies in yeast cells treated with hydrogen peroxide}

Treatments of budding yeast cells with hydrogen peroxide and mixtures hydrogen peroxide-iodine (followed by washing with water) increased numbers of small colonies on solid YEPD. Their largest numbers $36.8 \%$ of total colony number) were produced by cells treated with hydrogen peroxide at concentration $3 \mathrm{mM}$ (Figure 1b). After treatment with $1.5 \mathrm{mM}$ hydrogen peroxide the slight increase in the number of small colonies $(18 \%$ as average) was not statistically significant as compared with control (11\% of small colonies). Treatments with up to $200 \mathrm{mM}$ iodine did not increase numbers of small colonies $(12 \%)$. However, cells treated with the mixture of hydrogen peroxide-iodine $(1.5 \mathrm{mM}+200 \mu \mathrm{M}$ respectively) produced $34 \%$ of small colonies suggesting a cooperative effect between hydrogen peroxide and iodine. Under these treatment conditions cells were clearly inhibited but were still able to grow.

We reasoned that small colonies might present the petite mutants associated with mutations in mitochondrial DNA leading to respiratory deficiencies. The petite mutants are not able to grow under respiration conditions, for example, on glycerol or ethanol [43]. Indeed, most of randomly selected individual small colonies from treatments with $3 \mathrm{mM}$ hydrogen peroxide $(78 \%)$ and with the mixture $1.5 \mathrm{mM}$ hydrogen peroxide $+200 \mu \mathrm{M}$ iodine (79\%) were not able to grow on YEPG medium and, therefore, were respiratory deficient (data not shown).

The increased incidence of petite mutants indicates that the antimicrobials produce genotoxic effects. In case of hydrogen peroxide they could be associated with oxidative stress via intensive generation of reactive oxygen species that enhance mutation rates [44]. Iodine itself did not affect spontaneous frequencies of small colonies. However, combined with hydrogen peroxide, iodine enhanced the effect of this compound (Figure 1b) suggesting some additional (possibly, co-operative) contribution to the genotoxic effect of hydrogen peroxide. Since the respiratory deficient yeast mutants are easily detectable, this approach could be potentially used for scoring genotoxic effects of any other antimicrobials (including new ones) - based on numbers of small colonies appearing after treatments. The enhanced genotoxicity itself could contribute to stronger biocidal effects against microorganisms. On the other hand, genotoxicity might increase chances for microbial mutations of drug resistance. However, the biocidal activity of the combined antimicrobials at appropriate concentrations would prevent the survival of mutants. The other potential issue is genotoxicity of antimicrobials for human cells. Overall, interplay between these processes could be the subject of further studies.

\section{Conclusions}

Synergistic and additive inhibitory effects of hydrogen peroxide and iodine shown for 3 bacterial and 16 yeast species imply possibilities of more effective concurrent usage of these traditional antimicrobials in various applications. Combining these compounds often converts their individual static inhibitory effects into cidal effects. Synergism is also manifested in higher frequencies of respiratory deficient yeast cells suggesting enhanced genotoxicity of the mixed antimicrobials.

\section{Methods}

\section{Strains and culture conditions}

3 bacterial and 16 yeast species were used (Additional file 1: Table S1). Bacteria were cultivated on nutrient agar or in nutrient broth for one day at $37^{\circ} \mathrm{C}$. Yeasts were cultivated on solid or liquid YEPD (yeast extract, peptone, dextrose) medium at $30^{\circ} \mathrm{C}$ for 2 days or at $23^{\circ} \mathrm{C}$ for 3 days. Fresh yeast cultures were used to inoculate liquid YEPD medium at densities about $5 \times 10^{5}$ cells $/ \mathrm{ml}$. Single colonies of bacterial strains cultivated on nutrient agar at $37^{\circ} \mathrm{C}$ for 16-18 hours were used for inoculating nutrient broth at densities of approximately $5 \times 10^{5}$ cells $/ \mathrm{ml}$. 


\section{Spot tests}

Fresh yeast cells grown in YEPD were resuspended in sterile distilled water to OD $\sim 0.5$ at $660 \mathrm{~nm} .5$ fold serial dilutions of each strain in 96-well plates (200 $\mu$ l each) were plated in two replicas with Sigma-Aldrich plater onto YEPD plates with iodine and/or hydrogen peroxide, or without them. Plates were incubated at $23^{\circ} \mathrm{C}$ for 3 days.

\section{Determination of minimum inhibitory concentration (MIC)} MIC values were determined separately for hydrogen peroxide and iodine (Sigma). The aqueous stock solution of iodine (product number 318981) contained KI as a solubility stabiliser. $2 \mathrm{ml}$ of cultures $\left(5 \times 10^{5}\right.$ cells $\left./ \mathrm{ml}\right)$ were added to test tubes, and different amounts from serial dilutions of $1 \mathrm{M} \mathrm{H}_{2} \mathrm{O}_{2}$ or $50 \mathrm{mM} \mathrm{I}_{2}$ stock solutions were added to the cultures to obtain a range of concentrations $\left(10 \mu \mathrm{M}-10 \mathrm{mM}\right.$ for $\mathrm{H}_{2} \mathrm{O}_{2}$, and $10 \mu \mathrm{M}$ $1 \mathrm{mM}$ for $\mathrm{I}_{2}$ ). Cultures were incubated at $30^{\circ} \mathrm{C}$ for 2 days (yeast) and at $37^{\circ} \mathrm{C}$ for $1-2$ days (bacteria) to determine MICs (the lowest concentrations preventing growth).

\section{Determination of the interaction mode between hydrogen peroxide and iodine}

To determine MICs for individual mixtures of both compounds, serial dilutions of $\mathrm{H}_{2} \mathrm{O}_{2}$ and $\mathrm{I}_{2}$ were combined in test tubes containing $2 \mathrm{ml}$ of cultures $\left(\sim 5 \times 10^{5}\right.$ cells $\left./ \mathrm{ml}\right)$. Cultures were incubated at $30^{\circ} \mathrm{C}$ for 2 days (yeast) or at $37^{\circ} \mathrm{C}$ for $1-2$ days (bacteria). MIC values for each $\mathrm{H}_{2} \mathrm{O}_{2}-\mathrm{I}_{2}$ mixture were determined as described above. Fractional inhibitory concentration (FIC) of each compound was calculated according to the formula: $\mathrm{FIC}=\mathrm{MIC}$ of a compound in a mix/MIC of a compound alone [26,36]. The sum of fractional inhibitory concentrations (FICs) was calculated as follows: $\mathrm{FICs}=\mathrm{FIC}_{\text {hydrogen }}$ peroxide $+\mathrm{FIC}_{\text {iodine }}$ FICs indices less than 1 were interpreted as weak synergistic interactions or strong additive effects.

\section{Tests for growth recovery after inhibition with biocides}

To test if growth inhibition was caused by cell death or by static inhibition of cell divisions, cells were washed from biocides 2 times with nutrient broth (for bacteria) or sterile distilled water (for yeast), and their serial dilutions were plated on freshly poured solid media for counting colonies after 1 and 2 days of growth at $30^{\circ} \mathrm{C}$ (yeast) and $37^{\circ} \mathrm{C}$ (bacteria).

\section{Testing respiratory status of S. cerevisiae clones}

Water suspensions of randomly selected individual small colonies were patched onto two types of solid media: YEPD (containing glucose, 2\%) and YEPG (containing glycerol, 3\%). Plates were incubated for 2.5-3 days at $30^{\circ} \mathrm{C}$. Cells growing only on YEPD (fermentation conditions) but not growing on YEPG (respiration conditions) were classified as respiratory deficient mutants; cells growing on both media were considered as respiratory proficient [43].

\section{Statistical analysis}

Quantitative data were presented as means and standard deviations (SD). Differences with P values less than 0.05 determined in t-tests were considered as significant.

\section{Additional files}

\begin{abstract}
Additional file 1: Table S1. Microorganisms used in the study. [45,46]. Additional file 2: Table S2. Growth responses of budding yeast (S. cerevisiae) and three bacterial species (S.aureus, P. aeruginosa and E.coli) to different concentrations of $\mathrm{H}_{2} \mathrm{O}_{2}$ and $\mathrm{I}_{2}$ in culture media.

Additional file 3: Figure S1. Growth responses of $P$. aeruginosa to different concentrations of $\mathrm{I}_{2}(\mathbf{a}), \mathrm{H}_{2} \mathrm{O}_{2}$ (b) and mixtures of $\mathrm{I}_{2}$ and $\mathrm{H}_{2} \mathrm{O}_{2}$ at different concentrations in nutrient broth (c). (d) Recovery of the growth after inhibition with individual and mixed compounds. $20 \mu \mathrm{l}$ from undiluted cultures and from two different dilutions (100 fold and 1000 fold) were plated on each plate and grown overnight at $37^{\circ} \mathrm{C}$, with further checking on the next day. Figure S2. Growth responses (growth or no growth) of $\mathrm{S}$. aureus to different concentrations of $\mathrm{I}_{2}$ (a), $\mathrm{H}_{2} \mathrm{O}_{2}$ (b) and mixtures of $\mathrm{I}_{2}$ and $\mathrm{H}_{2} \mathrm{O}_{2}$ at different concentrations in nutrient broth (c). (d) Recovery of the growth after inhibition with individual and mixed compounds. $20 \mu \mathrm{l}$ from undiluted cultures and from two different dilutions (100 fold and 1000 fold) were plated on each plate and grown overnight at $37^{\circ} \mathrm{C}$, with further checking on the next day. Figure $\mathbf{S 3}$. Growth responses (growth or no growth) of S. cerevisiae to different concentrations of $\mathrm{I}_{2}$ (a), $\mathrm{H}_{2} \mathrm{O}_{2}$ (b) and mixtures of $\mathrm{I}_{2}$ and $\mathrm{H}_{2} \mathrm{O}_{2}$ at different concentrations in YEPD liquid medium (c). (d) Recovery of the growth after inhibition with individual and mixed compounds. Before plating cultures were diluted 1000 times and 100 times. In cases of mixed compounds, both diluted and undiluted cultures were plated. The plated were incubated for 2 days at $30^{\circ} \mathrm{C}$. Figure S4. Growth responses (growth or no growth) of E. coli to different concentrations of $\mathrm{I}_{2}$ (a), $\mathrm{H}_{2} \mathrm{O}_{2}$ (b) and mixtures of $\mathrm{I}_{2}$ and $\mathrm{H}_{2} \mathrm{O}_{2}$ at different concentrations in nutrient broth (c). (d) Recovery of the growth after inhibition with individual and mixed compounds. $20 \mu \mathrm{l}$ from undiluted cultures and from two different dilutions (100 fold and 1000 fold) were plated on each plate and grown overnight at $37^{\circ} \mathrm{C}$, with further checking on the next day.
\end{abstract}

\section{Competing interests}

The authors declare that they have no competing interests.

\section{Authors' contributions}

EIZ and MKZ designed the study. EIZ has performed predominant part of experiments. MKZ did spot tests and wrote the bulk of the manuscript. EIZ calculated data and made tables and figures. Both authors approved the final version of the manuscript.

\section{Acknowledgements}

We thank the Faculty of Science and Engineering for providing financial start-up support for this work, and Dr. Gordon Craig (School of Science \&The Environment at $\mathrm{MMU}$ ) for reading the manuscript. We also thank anonymous reviewers for their constructive suggestions.

Received: 27 February 2013 Accepted: 4 July 2013

Published: 15 July 2013

\section{References}

1. McDonnell G, Russell AD: Antiseptics and disinfectants: activity, action, and resistance. Clin Microbiol Rev 1999, 12(1):147-179.

2. Bowler PG, Duerden BI, Armstrong DG: Wound microbiology and associated approaches to wound management. Clin Microbiol Rev 2001, 14(2):244-269. 
3. Mermel LA: Prevention of intravascular catheter-related infections. Ann Intern Med 2000, 132(5):391-402.

4. Durani $P$, Leaper D: Povidone-iodine: use in hand disinfection, skin preparation and antiseptic irrigation. Int Wound J 2008, 5(3):376-387.

5. Falagas ME, Thomaidis PC, Kotsantis IK, Sgouros K, Samonis G, Karageorgopoulos DE: Airborne hydrogen peroxide for disinfection of the hospital environment and infection control: a systematic review. J Hosp Infect 2011, 78(3):171-177.

6. Kanno T, Nakamura K, Ikai H, Kikuchi K, Sasaki K, Niwano Y: Literature review of the role of hydroxyl radicals in chemically-induced mutagenicity and carcinogenicity for the risk assessment of a disinfection system utilizing photolysis of hydrogen peroxide. J Clin Biochem Nutr 2012, 51(1):9-14.

7. Cutting KF, Butcher M: DACC antimicrobial technology: a new paradigm in bioburden management. J Wound Care 2011, 20(5):1-19.

8. Mueller RS, Bergvall K, Bensignor E, Bond R: A review of topical therapy for skin infections with bacteria and yeast. Vet Dermatol 2012, 23(4):330-e362.

9. Cutting KF: A dedicated follower of fashion? topical medications and wounds. Br J Community Nurs 2001, 6(8):9-16.

10. Cutting KF: Wound healing through synergy of hyaluronan and an iodine complex. J Wound Care 2011, 20(9):424-430.

11. O'Meara S, Al-Kurdi D, Ologun Y, Ovington LG: Antibiotics and antiseptics for venous leg ulcers. Cochrane Database Syst Rev 2010, 10:1-79.

12. Tschudin-Sutter S, Frei R, Egli-Gany D, Eckstein F, Valderrabano V, Dangel M, Battegay $M$, Widmer AF: No risk of surgical site infections from residual bacteria after disinfection with povidone-iodine-alcohol in 1014 cases a prospective observational study. Ann Surg 2012, 255(3):565-569.

13. Eley BM: Antibacterial agents in the control of supragingival plaque - a review. Br Dent J 1999, 186(6):286-296.

14. Presterl E, Suchomel M, Eder M, Reichmann S, Lassnigg A, Graninger W, Rotter M: Effects of alcohols, povidone-iodine and hydrogen peroxide on biofilms of Staphylococcus epidermidis. J Antimicrob Chemother 2007, 60 (2):417-420.

15. Atakan $\mathrm{H}$, Kaplan M, Kaya $\mathrm{E}$, Aktoz $\mathrm{T}$, Inci $\mathrm{O}$ : A life-threatening infection: Fournier's gangrene. Int Urol Nephrol 2002, 34(3):387-392.

16. Jansen B, Kristinsson KG, Jansen S, Peters G, Pulverer G: In-vitro efficacy of a central venous catheter complexed with iodine to prevent bacterial colonization. J Antimicrob Chemother 1992, 30(2):135-139.

17. Malik DJ, Shaw CM, Rielly CD, Shama G: The inactivation of Bacillus subtilis spores at low concentrations of hydrogen peroxide vapour. J Food Eng 2013, 114(3):391-396

18. Arndt RE, Wagner EJ, Routledge MD: Reducing or withholding hydrogen peroxide treatment during a critical stage of rainbow trout development: effects on eyed eggs, hatch, deformities, and fungal control. North Am J Aquaculture 2001, 63(2):161-166

19. Wagner EJ, Oplinger RW, Bartley M: Laboratory and production scale disinfection of salmonid eggs with hydrogen peroxide. North Am J Aquaculture 2012, 74(1):92-99.

20. Ukuku DO, Bari ML, Kawamoto S, Isshiki K: Use of hydrogen peroxide in combination with nisin, sodium lactate and citric acid for reducing transfer of bacterial pathogens from whole melon surfaces to fresh-cut pieces. Int J Food Microbiol 2005, 104(2):225-233.

21. Kim BR, Anderson JE, Mueller SA, Gaines WA, Kendall AM: Literature review - efficacy of various disinfectants against Legionella in water systems. Water Res 2002, 36(18):4433-4444.

22. Carlsson J, Edlund MB, Hanstrom L: Bactericidal and cytotoxic effects of hypothiocyanite-hydrogen peroxide mixtures. Infect Immun 1984 44(3):581-586

23. Miyasaki KT, Genco RJ, Wilson ME: Antimicrobial properties of hydrogen peroxide and sodium bicarbonate individually and in combination against selected oral, gram-negative, facultative bacteria. J Dent Res 1986 65(9):1142-1148.

24. Humphrey TJ: The synergistic inhibition of Campylobacter jejuni by rifampicin and hydrogen peroxide. Lett App/ Microbio/ 1990, 10(2):97-100.

25. Almeida CEB, Felicio DL, Galhardo RS, Cabral-Neto JB, Leitao AC: Synergistic lethal effect between hydrogen peroxide and neocuproine (2,9-dimethyl 1,10-phenanthroline) in Escherichia coli. Mutation Research-DNA Repair 1999, 433(1):59-66.

26. Steinberg D, Heling I, Daniel I, Ginsburg I: Antibacterial synergistic effect of chlorhexidine and hydrogen peroxide against Streptococcus sobrinus,
Streptococcus faecalis and Staphylococcus aureus. J Oral Rehabil 1999, 26(2):151-156

27. Martin H, Maris P: Synergism between hydrogen peroxide and seventeen acids against six bacterial strains. J App/ Microbiol 2012, 113(3):578-590.

28. Shama G: Inactivation of Escherichia coli by ultraviolet light and hydrogen peroxide in a thin film contactor. Lett Appl Microbiol 1992, 15(6):259-260

29. Markum E, Baillie J: Combination of essential oil of Melaleuca alternifolia and iodine in the treatment of Molluscum Contagiosum in children. J Drugs Dermatol 2012, 11(3):349-354.

30. Anderson MJ, Horn ME, Lin YC, Parks PJ, Peterson ML: Efficacy of concurrent application of chlorhexidine gluconate and povidone iodine against six nosocomial pathogens. Am J Infect Control 2010, 38(10):826-831.

31. Price SL, Huddersman KD, Shen J, Walsh SE: Mycobactericidal activity of hydrogen peroxide activated by a novel heterogeneous fentons-like catalyst system. Lett Appl Microbiol 2013, 56(2):83-87.

32. Voboril R, Weberova J: Successful treatment of infected vascular prosthetic grafts in the groin using conservative therapy with povidoneiodine solution. Ann Vasc Surg 2004, 18(3):372-375.

33. Ulivieri S, Toninelli S, Petrini C, Giorgio A, Oliveri G: Prevention of postoperative infections in spine surgery by wound irrigation with a solution of povidone-iodine and hydrogen peroxide. Arch Orthop Trauma Surg 2011, 131(9):1203-1206.

34. Ng SM, Wieckowski S: Stable hydrogen peroxide dental gel. US Patent-4839156. Colgate-Palmolive Company; 1989. 1199.

35. Cassee FR, Groten JP, van Bladeren PJ, Feron VJ: Toxicological evaluation and risk assessment of chemical mixtures. Crit Rev Toxicol 1998, 28(1):73-101.

36. Chung PY, Navaratnam P, Chung LY: Synergistic antimicrobial activity between pentacyclic triterpenoids and antibiotics against Staphylococcus aureus strains. Ann Clin Microbiol Antimicrob 2011, 10(25):1-6.

37. Hall MJ, Middleton RF, Westmacott D: The fractional inhibitory concentration (FIC) index as a measure of synergy. J Antimicrob Chemother 1983, 11:427-433.

38. Burkhart CG, Burkhart CN, Isham N: Synergistic antimicrobial activity by combining an allylamine with benzoyl peroxide with expanded coverage against yeast and bacterial species. Br J Dermatol 2006, 154(2):341-344.

39. Fraunfelder FW, Rich LF: Possible adverse effects of drugs used in refractive surgery. J Cataract Refract Surg 2003, 29(1):170-175.

40. Tredwin CJ, Naik S, Lewis NJ, Scully C: Hydrogen peroxide tooth-whitening (bleaching) products: review of adverse effects and safety issues. $\mathrm{Br}$ Dent J 2006, 200(7):371-376.

41. Oberg TS, Steele JL, Ingham SC, Smeianov W, Briczinski EP, Abdalla A, Broadbent JR: Intrinsic and inducible resistance to hydrogen peroxide in Bifidobacterium species. J Ind Microbiol Biotechnol 2011, 38(12):1947-1953.

42. Brown ML, Aldrich HC, Gauthier JJ: Relationship between glycocalyx and povidone-iodine resistance in Pseudomonas aeruginosa (ATCC 27853) biofilms. Appl Environ Microbiol 1995, 61(1):187-193.

43. Bulder CJEA: Induction of petite mutation and inhibition of synthesis of respiratory enzymes in various yeasts. Antonie Van Leeuwenhoek 1964, 30:1-9

44. Orrenius S, Gogvadze A, Zhivotovsky B: Mitochondrial oxidative stress: Implications for cell death. In Annual Review of Pharmacology and Toxicology, Volume 47. Palo Alto: Annual Reviews; 2007:143-183.

45. Rodger G, Taylor RL, Pearson GJ, Verran J: In Vitro colonization of an experimental silicone by Candida albicans. J Biomed Mater Res B Appl Biomater 2010, 92B(1):226-235.

46. Zubko MK, Lydall D: Linear chromosome maintenance in the absence of essential telomere-capping proteins. Nat Cell Biol 2006, 8(7):734-740.

doi:10.1186/1756-0500-6-272

Cite this article as: Zubko and Zubko: Co-operative inhibitory effects of hydrogen peroxide and iodine against bacterial and yeast species. BMC Research Notes 2013 6:272. 